\title{
Impact of Fat and Sugar Levels on Physico-Chemical and Microbial Qualities of Chocolate Milk Drinks
}

\author{
Satish Kumar* \\ Department of Animal Husbandry and Dairying, C.S. Azad University of Agriculture and \\ technology, Kanpur-208002, India \\ *Corresponding author
}

\section{A B S T R A C T}

Keywords

Chocolate milk drinks, Cocoa powder, Physicochemical and microbial qualities.

Article Info

Accepted:

21 August 2017

Available Online:

10 September 2017
The study was related to Impact of fat and sugar levels on physic-chemical and microbial qualities of Chocolate milk drinks from cow milk with 18 combination of milk fat (3), sugar (3), and cocoa powder (2). The suitability of final product assessed on the basis of their sensory (using 100 point scale), chemical and microbial analysis. Factorial Randomized Design was used to test the significance of various process variables. The study revealed that the chocolate milk drinks manufactured by adding $2 \%$ fat milk, $7 \%$ sugar and $2 \%$ cocoa powder had the highest overall acceptability. It makes more palatable and stimulates the sale of milk besides increasing profitable use of skim milk.

\section{Introduction}

Milk is the most wholesome nutritious and nearly complete food available in nature for growth and maintenance of health for person one year age and older. The western and northern region consume a major amount of milk in direct or indirect liquid from on the other hand, milk consumption in the southern and eastern region is largely through tea and coffee. Out of the total milk, $46 \%$ is used as fluid and $7 \%$ as curd (Anonymous, 2002).

Low fat milk is well known for their digestibility and nutrients i.e. proteins, lactose, minerals and vitamins. The production of low fat milk beverage is one of the most economic feasible options of skim milk. Low fat milk beverage shall invite greater consumer acceptability than the beverage prepared from whole milk due to its relative low cost, less viscosity and low fat content. When the fat level of flavoured milk is lower $(1-2 \%)$ to the minimum legal standard (4\%) the term drink is used (De, 1986).

The purpose of the present investigation is to make milk more palatable, to those who do not relish it as such, stimulate the sale of milk and to put skim milk to profitable use. Since the drink could be produced from cocoa powder (Theobroma cacao), it has been name chocolate milk drinks. 


\section{Materials and Methods}

\section{Collection of milk}

The required quantity of fresh mixed cow's milk was procured from the experimental dairy farm of the Chandra Shekhar Azad university of Agriculture and Technology Kanpur.

\section{Standardization}

To get required quantity of skim milk, fresh cow milk is separated carefully in a cream separator. The whole cow's mixed milk and the skim milk is worked out for the preparation of standardized milk containing $1 \%\left(\mathrm{~F}_{1}\right), 1.5 \%\left(\mathrm{~F}_{2}\right)$, and $2 \%\left(\mathrm{~F}_{3}\right)$ milk fat. The required amount of whole milk and skim milk mixed together as per calculation by Pearson's square method.

\section{Cocoa powder}

Good quality cocoa powder with assured higher solubility, manufactured by M/s All Times Food Pvt. Ltd., 55/ Ezra Street Calcutta was purchased from local market of Kanpur city.

\section{Sugar and stabilizer}

Commercial grade white crystalline cane sugar was used as sweetening agent free from dust, dirt and any other foreign materials. Only pure form of stabilizer named sodium alginate was used in the preparation of chocolate milk drinks.

\section{Formulation}

To prepare the chocolate milk drinks, the fallowing formulations were used:-

Cocoa powder - $1 \%$ and $2 \%$

Sugar $-5 \%, 6 \%$ and $7 \%$

Sodium alginate - @ $0.2 \%$.

\section{Preparation of chocolate milk drinks}

Standardized milk was heated to 35 to $40^{\circ} \mathrm{C}$ in a double jacketed stainless steel vat with constant stirring by a stainless steel ladle. Weighed quantity of sugar was dissolved in a beaker @ 50,60 and 70g/l. of milk and mixed well to milk used for the preparation of chocolate milk drinks to prepare chocolate milk drinks containing 5\%, $6 \%$ and $7 \%$ sugar.

Separately cocoa powder @ 10 and 20g/l. of milk was taken in a beaker and made to a homogenous paste with $50 \mathrm{ml}$ warmed milk and mixed well to the milk used for the preparation of drinks.

Sodium alginate $(2 \mathrm{~g})$ was taken in a beaker and made a solution with $100 \mathrm{ml}$ of warmed milk (35 to $40^{\circ} \mathrm{C}$ ) and heated until it was completely dissolved in the milk and mixed well to the milk. Milk was strained through muslin cloth to separate undissolved sodium alginate, cocoa powder and other foreign materials like milk soils.

After thorough mixing, the milk was heated at $72^{0} \mathrm{C}$ for 30 minutes and cooled immediately after heating over a surface cooler to $25^{0} \mathrm{C}$.

After cooling the product was filled in $200 \mathrm{ml}$. glass bottles, which were properly cleaned and sterilized before filling. The bottles were filled up to the neck with chocolate milk drinks and sealed with crown cork using corking machine and transferred to refrigerator $\left(4\right.$ to $\left.7^{0} \mathrm{C}\right)$ for various length of time to observe its period of spoilage and analysis for various parameters.

\section{Chemical and microbiological analysis}

Chocolate milk drinks samples were tested for total solids and ash contents (IS: 1479, Part II, 1961). The Standard Plate counts (SPC) and Coliform counts were determined as per the standard method described in BIS: 1962. 


\section{Sensory evaluation}

The sensory evaluations of chocolate milk drink samples were carried out a panel of judge on a 100 points scale given by the United State Department of Agriculture Bureau of Dairy Industry by American Dairy Science Association (Nelson and Malcalum, 1964). The samples were evaluated for colour and appearance, flavor, sweetness, sediment, packaging and overall acceptability as per schedule.

\section{Results and Discussion}

\section{Total solids content}

The average total solids content on account of various fat, sugar and cocoa levels ranged from 16.64 to 18.5 with an overall average of 17.58 per cent (Table 1). The total solids content increased significantly with increase of fat, sugar and cocoa levels, higher total solids content were recorded when the product prepared using $2 \%$ fat milk,7\% sugar and $2 \%$ cocoa powder. So far no one else has reported impact of fat, sugar and cocoa levels on total solids content of chocolate milk drinks.

\section{Ash contents}

Table 1 showing average ash content of chocolate milk drinks of various fat, sugar and cocoa levels ranged from 0.695 to 0.697 with an overall average of 0.696 per cent.

The effect of fat, sugar and cocoa levels on ash content of chocolate milk drinks was nonsignificant. No one else has studied the effect of fat, sugar and cocoa levels on ash content of chocolate milk drinks so far.

\section{Standard plate count (SPC/ml.)}

The effect of various sugar and cocoa levels on $\mathrm{SPC} / \mathrm{ml}$. of chocolate milk drinks was significant at $1 \%$ level of significance, while the effect of fat on SPC was non-significant. Average SPC on account of various fat, sugar and cocoa levels ranged from 3144 to 3617 with an overall average of $3307 \mathrm{SPC} / \mathrm{ml}$. (Table 1). Lowest SPC/ml. of chocolate milk drinks was noted when the drinks prepared with $1 \%$ cocoa and $1 \%$ fat. Standard plate count $/ \mathrm{ml}$. of chocolate milk drinks was less than the ISI Standard $(50,000 \mathrm{SPC} / \mathrm{ml})$ recommended for flavoured milk (pasteurized).

The chocolate milk drinks samples were analyzed for coliform count. Since the drinks samples were pasteurized before filling in to bottles, the coliform count almost all samples were found to be nil, which indicated that no post pasteurization contamination. Present study falls with the ISI Standards, which is recommended 10 coliform count/ $\mathrm{ml}$ flavoured milk (pasteurized).

\section{Colour and appearance}

The average colour and appearance scores for various fat, sugar and cocoa levels ranged from 6.07 to 8.17 with an overall average of 7.12. Higher colour and appearance score was observed when the chocolate milk drinks was prepared with $2 \%$ fat, $7 \%$ sugar and $2 \%$ cocoa powder (Table 2). The level of fat, sugar and cocoa directly related to the colour and appearance score of the finished product.

The effect of fat, sugar and cocoa levels on colour and appearance scores of chocolate milk drinks was found to be significant at 1.0 level of significance. No work appears to have been done on this aspect.

\section{Flavour}

The average flavour scores of chocolate milk drinks on account of various fat, sugar and cocoa levels ranged from 35.37 to 40.18 with an overall average of 37.45 out of 45 (Table 2). 
Table.1 Effect of fat, sugar and cocoa levels on the sensory qualities of chocolate milk drinks

\begin{tabular}{cccc}
\hline Process variables & \multicolumn{2}{c}{ Chemical characteristics } & Microbiological characteristics \\
\hline & Total solids & Ash contents & Standard plate counts $/ \mathrm{ml}$ \\
& $(\%)$ & $(\%)$ &
\end{tabular}

A. Fat level

$(1 \%)$

$(1.5 \%)$

$(2 \%)$

$\mathrm{CD}(5 \%)$

B. Sugar levels

$(5 \%)$

$(6 \%)$

$(7 \%)$

$\mathrm{CD}(5 \%)$

C. Cocoa levels

(1\%)

(2\%)

$\mathrm{CD}(5 \%)$
16.99

17.81

17.96

1.76

16.64

17.60

18.51

0.15

17.04

18.13

0.12
0.697

0.696

0.695

N.S.

0.697

0.696

0.695

N.S.

0.696

0.696

N.S.
3453

3290

3178

N.S.

N.S.: Non-significant

Table.2 Effect of fat, sugar and cocoa levels on the sensory qualities of chocolate milk drinks

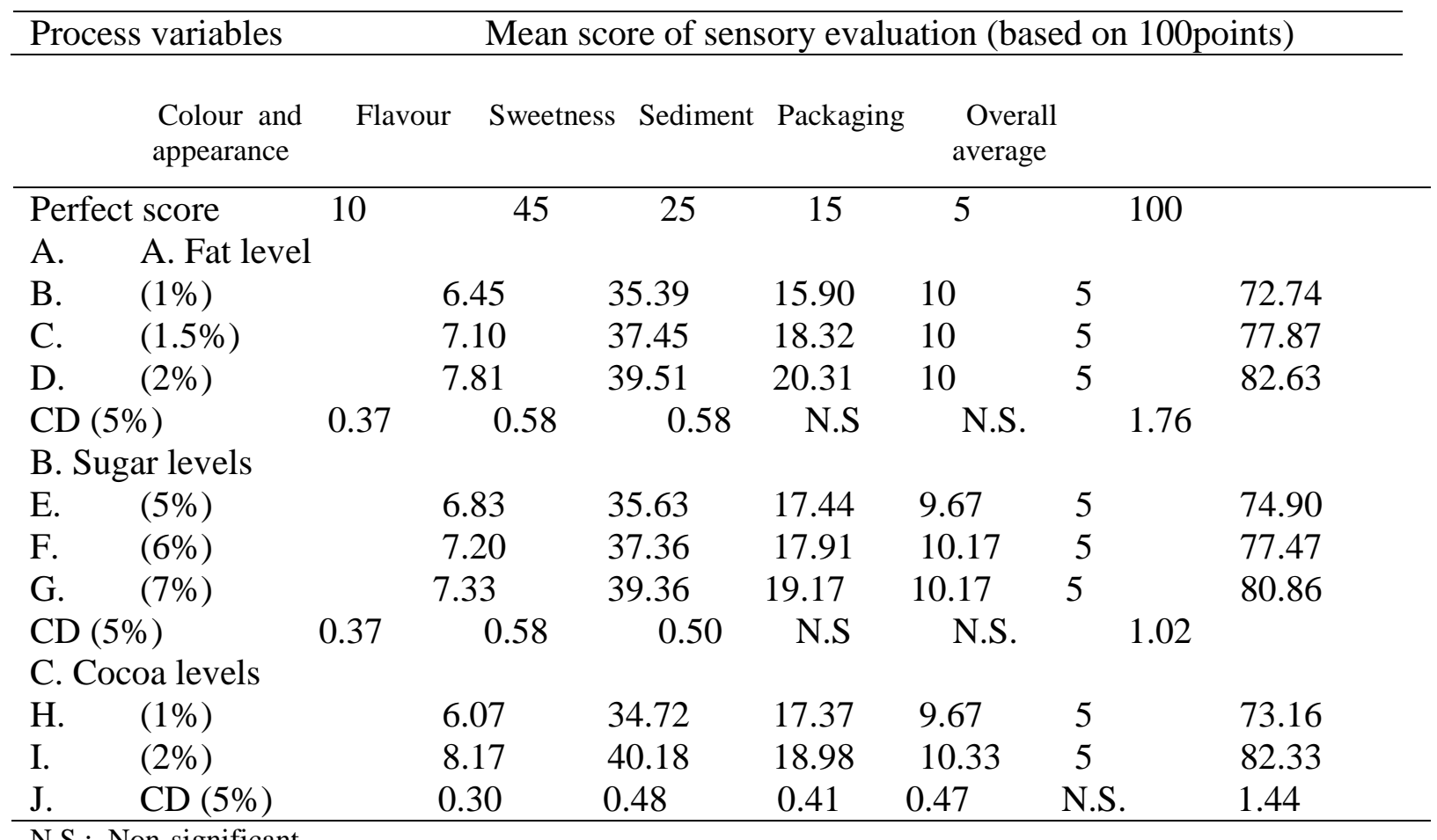

N.S.: Non-significant

Flavour scores increased significantly with increase in levels of fat, sugar and cocoa, which 
directly affected the flavour scores of chocolate milk drinks. The higher flavor scores was noted when the chocolate milk drinks prepared with $2 \%$ fat, $7 \%$ sugar and $2 \%$ cocoa powder.

\section{Sweetness}

The average sweetness scores of chocolate milk drinks on account of various fat, sugar and cocoa levels ranged from 15.90 to 20.31 with an overall average of 18.17 out of 25 . Sweetness scores varied significantly on account of various fat, sugar and cocoa levels, score increases as the level of fat, sugar and cocoa increase, this indicated that the fat, sugar and cocoa level had significant effect over sweetness scores of chocolate milk drink highest(20.31) sweetness score was observed when the product prepared with $7 \%$ sugar. So far no one else has been studied the effect of fat, sugar and cocoa levels on sweetness score of chocolate milk drink.

\section{Sedimentation}

The setting of cocoa powder in chocolate milk drink is very common. The average sediment scores of chocolate milk drinks on account of various fat, sugar and cocoa levels ranged from 9.67 to 10.33 , which an overall average of 10 out of 15. Effect of cocoa levels on sediment scores of chocolate milk drinks found to be significant, while the sugar and fat had no effect on sediment score. Highest (10.33) sediment score was recorded when the product prepared using $2 \%$ cocoa powder. It indicates that only cocoa powder directly related with sedimentation. No one else studied the effect of fat, sugar and cocoa level of a sediment score of chocolate milk drinks so far.

Overall acceptability
The average acceptability scores as influenced by various fat, sugar and cocoa levels ranged from 79.05 to 82.50 with an overall average of 81.09 out of 100 . The effect of fat and cocoa levels on overall acceptability score of chocolate milk drinks was found to be significant at $1 \%$ level of significance, while the sugar had no effect (table. 2). Higher suitability scores were observed when the product prepared with the higher fat and cocoa level indicated that the fat and cocoa level was directly related to the overall acceptability Score of chocolate milk drinks.

From the foregoing results it was concluded that the chocolate milk drinks manufactured by adding milk testing $2 \%$ fat, $7 \%$ sugar and $2 \%$ cocoa had the overall highest acceptability. It may be recommended for general public to make the milk more palatable and stimulate the sale of milk besides increasing profitable use of skim milk.

\section{References}

Anonymous, 2002, Indian dairyman, 54(2), 101. De, S., 1997. Outlines of dairy technology pp.99

Holsinger, V.H., and P.W. 1987. J. Dairy Sc. 70(6) 1159-1167

IS: 1479 1961. Bureau of Indian Standards Manak Bhavan, New Delhi.

IS: 1479 1962. Bureau of Indian Standards Manak Bhavan, New Delhi.

Nelson, john A., and Malcalum, Trout G. 1964. Judging dairy Products. Fourth Edi. pp 75-76.

Prasad, Sitaram and Katare, B.C. 2002. Indian Dairyman, 54(3) 43.

\section{How to cite this article:}

Satish Kumar. 2017. Impact of Fat and Sugar Levels on Physico-Chemical and Microbial Qualities of Chocolate Milk Drinks. Int.J.Curr.Microbiol.App.Sci. 6(9): 2007-2011.

doi: https://doi.org/10.20546/ijcmas.2017.609.246 